\title{
Low-Temperature X-ray Structure Techniques for the Characterization of Thermolabile Molecules
}

\author{
MICHAEL VEITH* and WALTER FRANK \\ Universität des Saarlandes, Anorganische Chemie, D-6600 Saarbrücken, Federal Republic of Germany
}

Received April 3, 1987 (Revised Manuscript Received July 23, 1987)

\section{Contents}

I. Introduction

A. General Aspects

B. Brief Comparison of the Methods for the Characterization of Unstable Intermediates

II. Methods and Devices

A. General Remarks

B. Main Elements of Gas Stream X-ray Diffraction Cooling Devices

1. Basic Principles

2. Gas Supply Unit

3. Delivery Nozzle

4. Transfer Line

5. Refill System

6. Automatic Temperature Control

C. Growth and Handling of Thermolabile Single Crystals

1. Crystal Growth in a Capillary

2. Crystal Growth in One Place and

Transfer to the Diffraction Device under Protective Conditions Elsewhere

III. Use of Three-Dimensional Structures of Unstable Inorganic Molecules and Solids in the Evaluation of Their Reactivity

A. Correlation of Instability and Molecular Structure

B. Reaction Intermediates

C. Unstable Phases in Solid-State Chemistry

IV. Conclusion and Outlook

V. Acknowledgments

VI. References
81

81

82

82

82

83

83

83

84

84

84

85

85

85

86

87

87

89

90

90

90

90

\section{Introduction}

\section{A. General Aspects}

The chemist is currently confronted with compounds that are unstable for either kinetic or thermodynamic reasons. If these compounds are produced during the course of a reaction sequence, they are designated as reaction intermediates. As well as chemical procedures, a variety of physicochemical methods has been used (see next chapter) to elucidate the composition and three-dimensional structure of the intermediate. The most complete and exact results are obtained by diffraction methods, followed by three-dimensional structure determinations. With X-ray diffraction on single crystals, the sample has to be cooled because of its instability, and the crystal growth and transfer must be performed under low-temperature conditions.

In this review the special techniques for the synthesis and handling of single crystals of unstable compounds are described. As far as we know, there is only one

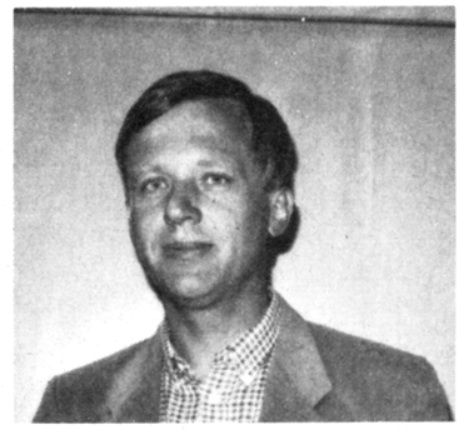

Michael Veith was born in 1944 in Goerlitz, Germany. He studied Chemistry at the University of Munich, where he received his Diplom-Chemiker degree in 1969. Continuing work with Prof. N. Wiberg he received his doctoral degree in 1971. He then moved to the University of Karlsruhe, where he started his postdoctoral work with Prof. H. Baernighausen. In 1977 he completed his Habilitation in inorganic chemistry. Until the end of 1978 he was Privat-Dozent at the University of Karsruhe. In 1979 he moved to the Technische Universitaet Braunschweig as a professor of inorganic chemistry. In 1984 he received offers for a full professorship at the University of Oldenburg, the University of Heidelberg, and the University of the Saarland (Saarbruecken). Since 1984 he has been in Saarbruecken. He has received several awards. His main interests are in the field of synthetic and structural chemistry, focusing on molecular compounds containing metallic elements.

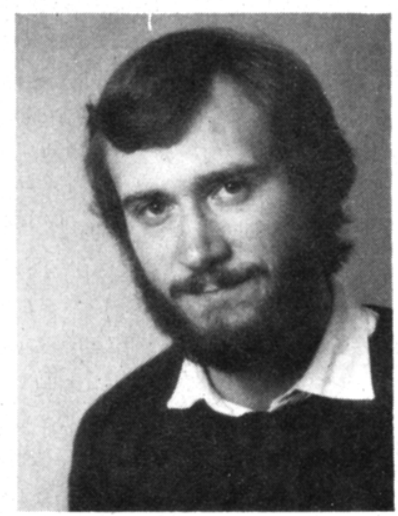

Walter Frank was born in 1957 in Munster, West Germany. He received his Diplom-Chemiker degree in 1982 and his Dr. rer. nat. after a two-year scholarship of the Stiftung Stipendien-Fonds der Chemischen Industrie at the Technische Universitaet Braunschweig with Prof. M. Veith. In 1984 he accepted a postdoctoral position at the University of the Saarland. He is currently working toward his Habilitation. His research interests are in the field of complexes of heavy metals, especially concerning preparative and structural aspects at the borderline between molecular and solid-state chemistry.

monograph, by Rudman. ${ }^{1}$ It appeared 10 years ago and referred to the different procedures of cooling. Solidstate and crystallographic problems also are widely discussed in this book. We intend here to focus on 
chemical problems on a molecular scale. To illustrate the capacity of the techniques described, a chapter has been included that is dedicated to the use of low-temperature crystallographic techniques in establishing reaction mechanisms (chapter III). The examples chosen are arbitrary and far from complete, but serve to demonstrate the different principles.

\section{B. Brief Comparison of the Methods for the Characterlzation of Unstable Intermediates}

Unstable intermediates are an important part of general chemistry, from both a theoretical and a practical point of view, and scientific journals exist devoted entirely to this special topic. ${ }^{2}$ To avoid confusion the term unstable intermediate or transient species as used in this review should be briefly characterized. This is not an unstable configuration of reacting atoms or molecules to which corresponds a maximum of potential energy in a reaction path. Such a "complex" cannot be frozen out and thus cannot be stabilized by altering a thermodynamic parameter such as the temperature. We define an intermediate in a given reaction as an atomic arrangement with a local minimum of potential energy but a higher energy than the reaction products.

When the composition and structure of a transient species are known, the most promising reactants may be selected, e.g., by mere steric considerations. Instead of 10-20 reaction partners, a much lower number has to be tested as exemplified in the reaction scheme (2) compared to the reaction scheme (1).

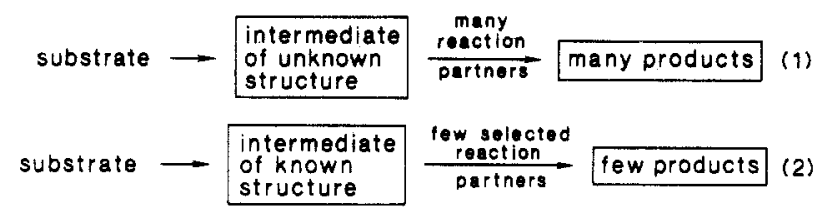

The advantage of the second scheme is that time is saved, leading to a better utilization of the synthetic procedure. There is, nevertheless, one difficulty: how can the structure of the intermediate be characterized correctly?

The physicochemical methods used for the determination of the structures of unstable molecules depend on the state of the matter. If the intermediate emerges from a substrate in the gas phase at reduced pressure, ${ }^{3}$ electron diffraction, ${ }^{4}$ photoelectron spectroscopy, ${ }^{5} \mathrm{UV}$ spectroscopy, ${ }^{6}$ microwave spectroscopy, ${ }^{7}$ or similar techniques can be used to characterize the compound. Easily the richest information can be derived from the diffraction experiment, as in this case the three-dimensional structure of the molecule can be established from a radial distribution function. ${ }^{4}$ If very small molecules are produced, matrix techniques can be used. In this procedure, the intermediate is frozen out at low temperatures in a noble gas environment, ${ }^{8}$ whereby infrared spectroscopy and Raman spectroscopy are generally used to characterize it. High resolution is then needed to evaluate the structure. ${ }^{9}$ ESR, SIMS, and NMR spectroscopy are also applied in these matrices ${ }^{10}$ as a means of characterizing the compound.

In solution, where most chemical reactions take place, a large variety of spectroscopic methods may be employed to determine the structure of the transient molecules. For more complicated intermediates, NMR techniques among others have proved to be very fruitful. ${ }^{11}$ A complete three-dimensional arrangement of the atoms within a molecule can, however, rarely be deduced from the spectra.

Solid-state NMR, ${ }^{12}$ ESCA, ${ }^{13}$ and Mössbauer spectroscopy ${ }^{14}$ are used in the solid state but X-ray diffraction on single crystals or crystal powders ${ }^{15,16}$ is the most widely used method to characterize metastable compounds or phases. In this last procedure the compound or phase under investigation has to be quenched to low temperatures in order to stabilize the phase for the diffraction experiment.

It is astonishing that this quenching method coupled with diffraction techniques has not been used more extensively for the determination of transient species in solutions or in the gas phase. There are, nevertheless, some cases in which this procedure may be employed quite easily. The central and most difficult point in these methods is the crystallization of the unstable intermediate. The difficulties may have several causes: (a) the crystallization of the intermediate may be hindered, (b) different solvents or temperatures may have to be tested, (c) products of side reactions may crystallize, (d) the substrates or products may crystallize more quickly than the intermediate, and (e) inclusion of solvents in the crystal may occur. Despite these problems the isolation can be attempted.

If the transient molecule can be stabilized in the gas phase under reduced pressure, its transformation to the crystalline state can be performed via sublimation on to a cold surface as exemplified in chapter II.C.

Crystallization of unstable compounds in solution, which is described in detail in chapter II.C, can be achieved if the energy of activation between the intermediate and the substrate (or substrates) is small enough to be attained at low temperatures, either by the environment or by a destinative radiation of the starting material. The equilibrium of a bimolecular primary process can often be shifted to the one-to-one intermediate by decreasing temperature (see example in chapter III).

\section{Methods and Devices}

\section{A. General Remarks}

Various procedures for cooling the specimen in X-ray diffraction studies have been proposed and were summarized by Stewart ${ }^{17}$ in a paper dealing with polycrystalline material. Rudman ${ }^{18}$ later reviewed the application of low-temperature techniques in light microscopy, IR, NMR, and ESR spectroscopy, and neutron diffraction to low-temperature X-ray diffraction. Robertson ${ }^{19}$ groups the numerous methods into three categories (gas cooling, liquid cooling, and conduction) and points out that several special requirements of single-crystal X-ray diffraction make gas stream cooling the most suitable technique for maintaining low temperatures. Early examples were reported by Cioffi and Taylor ${ }^{20}$ and by Eastman. ${ }^{21}$ Twenty-five years later the principles of this technique were rediscovered by Fankuchen and co-workers ${ }^{22}$ as well as by Lipscomb and his associates. ${ }^{23}$ With only minor modifications of the method a great number of crystal structures have been determined in a period of about 15 years. ${ }^{24}$

Commercial cooling equipment soon became available, ${ }^{25}$ and cooling attachments based on gas stream 


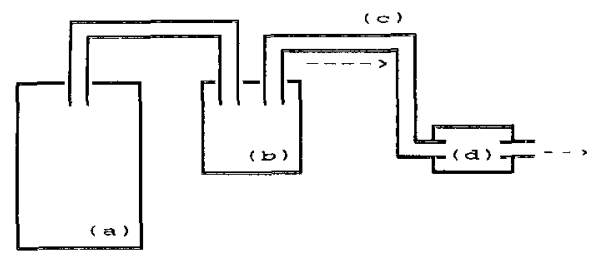

Figure 1. Main elements of gas stream cooling apparatus: (a) storage container for liquid cryogen; (b) gas stream supply unit; (c) transfer line; (d) cooling nozzle.

cooling techniques can be ordered as an accessory for Weissenberg cameras, Buerger precession cameras, four-circle diffractometers, and nearly all other types of diffraction devices.

Parallel to these developments of the cooling apparatus, methods were devised for obtaining single crystals from liquid or gaseous materials sealed in capillaries. There are few examples dealing with crystal growth of thermolabile materials in one place, followed by transfer to a low-temperature $\mathrm{X}$-ray device elsewhere.

In section $B$, the main elements of the most widely used gas stream low-temperature X-ray diffraction devices are shown; in section $\mathrm{C}$, techniques of single crystal growth at low temperatures and handling of such materials under protective conditions are outlined.

\section{B. Main Elements of Gas Stream X-ray Diffraction Cooling Devices.}

\section{Basic Principles}

The main elements of a gas stream cooling device in its most widely used form are shown in Figure 1. A cold gas is generated in a cold gas supply unit (b) and is directed through a transfer line (c) to a delivery nozzle (d). In this "open" kind of system the cooling gas escapes to the atmosphere and therefore it is necessary to refill the supply unit from a replenishing container (a). Elements for automatic temperature and refill control may be added but are not essential.

Alternatively "closed" crystal refrigeration systems have been proposed ${ }^{26 a, b}$ (Figure 2A), and two other types of cooling systems should be mentioned, which are often referred to as gas-stream-type devices, but which really are conduction-type devices using the categories mentioned before: ${ }^{19}$ the continuous-flow cryostat systems ${ }^{26 c, d}$ and the Joule-Thompson expansion systems. ${ }^{26 e, f}$ In these types also gas streams are used, but there is no direct contact of the cold gas with the specimen. The first type is shown in Figure 2B. In principle, it is merely a heat-conducting sample holder connected to a heat exchanger that is cooled by a continuous flow of cold gas or even liquid cryogen. In Figure 2C the principle of the Joule-Thompson refrigerator is outlined. High-pressure gas expands at the orifice (i). The cold gas stream formed in this way is directed toward the base of a metal sample holder (1) and leaves the refrigerator through a heat exchanger $(j)$ precooling the incoming high-pressure gas. A miniaturized version in the form of a modified goniometer head is available. ${ }^{26 f}$ In all these "closed"-type systems frost prevention has to be accomplished by using a sample chamber, and therefore windows for the path of X-rays are necessary. In the case of X-ray diffraction experiments beryllium and mylar have been used as materials. However, problems arise in correcting for
A

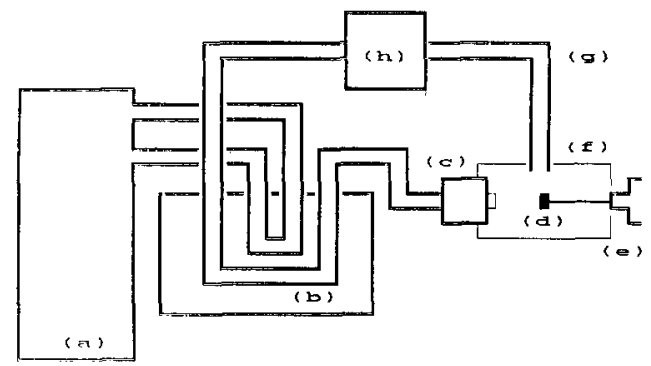

B

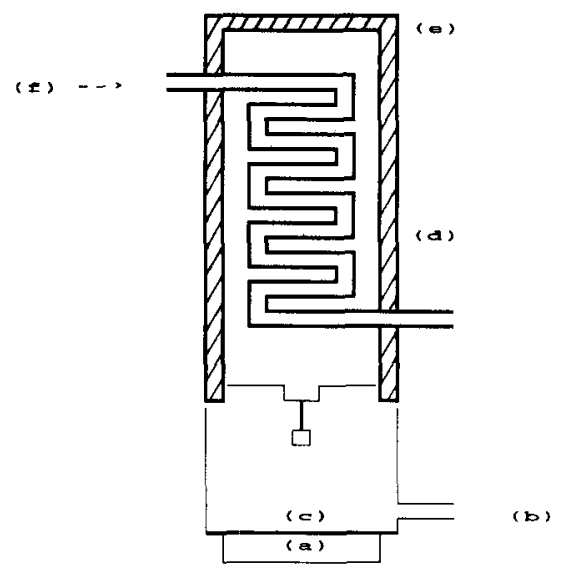

C

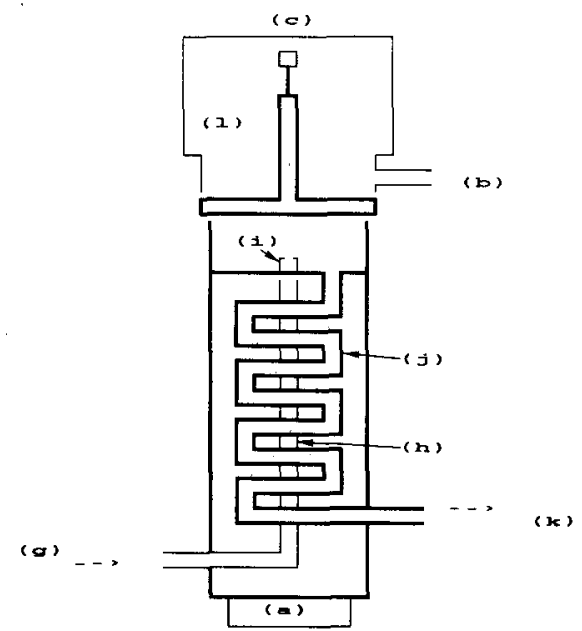

Figure 2. (A) Closed-cycle cooling: (a) cryostat; (b) heat exchanger; (c) cooling nozzle; (d) specimen; (e) goniometer head; (f) polyethene bag; (g) recirculation line; (h) circulating pump. (B) Continuous flow type cryostat: (a) connection to goniometer head; (b) evacuation port; (c) beryllium window; (d) heat exchanger incorporated in metal block; (e) insulation; (f) stream of cooling agent. (C) Joule-Thompson expansion cooling system: (a-c) same as for (B); (g) high-pressure gas inlet; (h) Joule-Thompson refrigeration unit; (i) orifice; (j) heat exchanger; (k) exhaust port; (l) metal crystal mount.

absorption of X-rays by these materials, and the closed geometry is a serious handicap if work with labile substances is to be done.

\section{Gas Supply Unit}

Young ${ }^{27}$ distinguishes three principal arrangements for generation of cold nitrogen gas (Figure 3): (1) bubbling gaseous nitrogen through liquid nitrogen; (2) passing the gas through a copper coil immersed in the liquid nitrogen; and (3) boiling liquid nitrogen with an immersed electric heater. In the first and last case, heat 

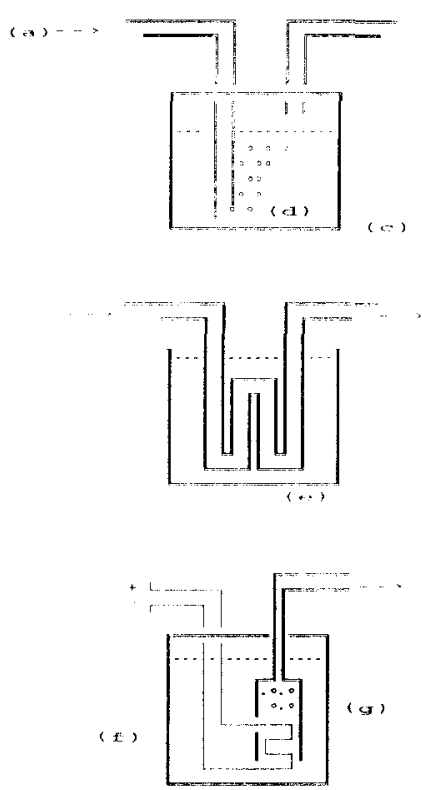

Figure 3. Main types of gas supply unit: (a) warm gas stream; (b) cold gas stream; (c) Dewar vessel; (d) liquid cryogen; (e) liquid cryogen or cooling liquid; (f) electric heater; (g) transfer line with evaporation tube.

transfer problems are completely eliminated, but nevertheless the "gas-bubbling method" 28 has never been of significance in low-temperature X-ray diffraction. The applicability of the second and third methods has been discussed by Abowitz and Ladell ${ }^{29}$ and the advantages of the "electrical evaporation method" were outlined in their paper.

Two main variations of this principle should be noted: the first involves a closed system, the gas being collected above the liquid and introduced into the transfer tube; the second is shown in Figure 3. The electric heating element (f) is embedded in a gas collection tube (g) connected to the transfer line. This arrangement allows the use of an unpressurized, open Dewar vessel. This is of importance for built-in elements controlling the level of the liquid cryogen. These elements influence the formation of excess gas and hence the flow rate of the gas stream. For constructive details in the field of gas supply units, the reader should consult the original papers (ref 29-39 for the evaporation technique and ref $26 \mathrm{~b}$ and $40-47$ for the heat exchange technique).

\section{Delivery Nozzle}

With the aid of the delivery nozzle a laminar flow gas stream of the desired diameter is generated and directed toward the specimen mounted on a goniometer head in front of the exit. The importance of laminar flow in the central region of the stream is stated by Young ${ }^{27}$ based on the analysis of heat transfer properties. It is desired to help minimize lateral gradients, to ensure dependable heat transfer from the specimen, and to prevent surrounding gases from entering the stream. If the specimen is sealed in a capillary, laminar flow is indispensable for maintaining the smallest possible temperature gradient along the capillary. In fact, the gas stream techniques easily achieve temperature uniformity at the crystal surface.

In practice (Figure 4), vacuum-jacketed tubes (c), surrounded by an additional tube (d) delivering a dry stream of gas at ambient temperature (b) or containing a heating coil (f), are employed as nozzles. Both con-
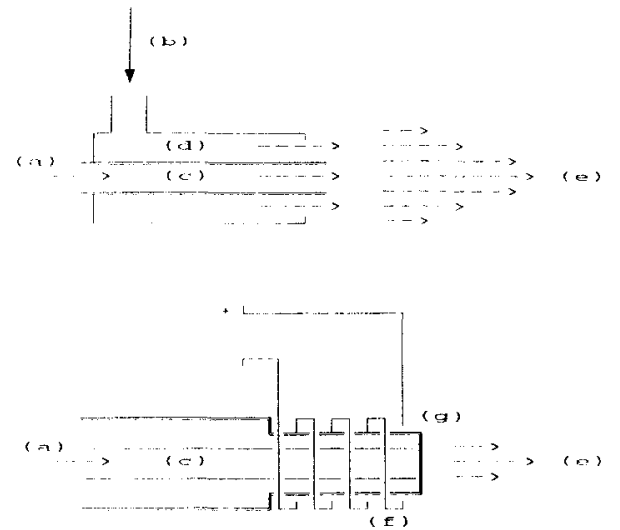

Figure 4. Cooling-gas nozzle: (a) cold gas stream from transfer line; (b) warm gas stream; (c) Dewar tube; (d) shielding gas supply tube; (e) cold gas stream with temperature gradient; (f) electrical heating element; $(\mathrm{g})$ metal tube.

structions are used to overcome the serious problem of frost formation at the crystal or capillary. A protective curtain of warm gas at the outside of the cold gas stream inhibits condensation of moisture from the surrounding air. In the first case, shielding gas may be dried air, ${ }^{22 b, 38}$ but often delivery is from a second boiling resistor immersed in the cold gas evaporation vessel, combined with an electric gas stream heater (see ref 48 and 49). In the second case, only one stream is needed, in which the border layers are warmed by passing through a heated metal tube placed at the end of the nozzle. $33,36,51,52$

Another idea for eliminating frost formation is to surround the whole diffraction device with a perspex enclosure containing dry air. ${ }^{23 b, 29,43,57,58}$

\section{Transfer Line}

Different types of transfer lines are in use, depending on the special requirements of the diffraction device. Rigid vacuum-jacketed tubes made of metal or silvered glass may be obtained if the nozzle is to be fixed in one position. Four-circle diffractometers are sometimes equipped with a nozzle attached to the $\chi$-circle in such a way that the cooling gas always flows in the $\varphi$-axial direction. ${ }^{49,51 b, 54}$ A flexible type of transfer line is necessary for this kind of arrangement. Hoses ${ }^{49}$ and rigid tubes connected by joints ${ }^{29,51 b, 55}$ are used.

\section{Refill System}

An uninterruptedly operating cooling device requires a refill system that will automatically transfer liquid cryogen from an external supply Dewar to the gas supply unit to maintain a constant level of the cooling agent within. ${ }^{56}$ During the refilling action, disturbance of the cold gas stream temperature should be avoided as far as possible.

Two alternative refill systems are shown in Figure 5. These systems differ principally in the control of the liquid cryogen level within the gas supply unit. The transport from the storage container to the evaporation vessel is effected by the pressure of the nitrogen gas above the liquid. The mechanically controlled system (Figure 5A) works by means of a methane-filled vapor pressure thermometer (e) controlling an outlet valve (d), which is connected to the storage container (a) by rubber tubing. If (e) is immersed in the liquid gas, (d) 
A

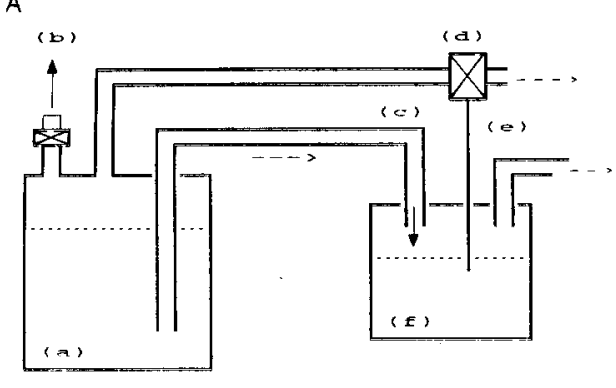

B

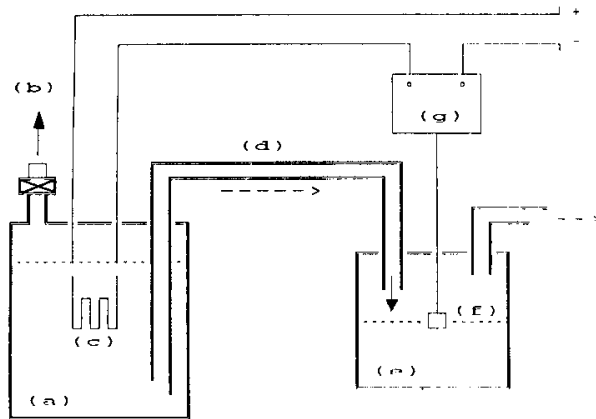

Figure 5. Automatic refill systems for evaporation vessel. (A) Mechanically controlled refill system: (a) replenishing vessel; (b) excess pressure relief valve; (c) refill line; (d) outlet valve; (e) vapor pressure thermometer; (f) evaporation vessel. (B) Electrically controlled refill system: (a) replenishing vessel; (b) relief valve; (c) electrical heater; (d) refill line; (e) evaporation vessel; (f) level sensor; (g) control unit.

opens and gas generated within (a) by heat leakage is directed to the atmosphere. If (e) loses contact with the liquid gas level, (d) closes and the rising pressure in (a) forces liquid to flow through the refill line (c).

The electrically controlled system (Figure $5 \mathrm{~B}$ ) contains an additional electric heater (c) and an NTC resistor, which serves as the level sensor. Alternatively, a controller consisting of a magnet riding on a level indicator float may be used. This activates magnetic reed switches attached to the exterior of this indicator. $^{37,59}$ A variation of this idea is refilling control by means of a photoelectric eye activated by the opaque top of a float. ${ }^{41,50}$

\section{Automatic Temperature Control}

The efficiency of gas stream temperature measurement with thermocouples was examined by Young. ${ }^{27}$ On the basis of his experiments on temperature control, he stated that rapid and well-controlled dynamic response to programmed temperature changes is provided by the gas stream method. Additional information concerning temperature measurement is given in ref 39 , 60 , and 61 .

As mentioned above, a cold gas stream may be supplied from a heat exchanger or from an evaporation vessel. For both techniques, a given crystal temperature can be obtained by variation of flow velocity of a gas maintained at a constant flow temperature, by a constant flow rate with variable supplementary heating, or by combining these two principles.

An automatic temperature control ${ }^{29}$ is illustrated in Figure 6. A thermocouple (g), fixed at the exit of the cooling nozzle (f), senses the temperature. An electronic control unit (d) compares it with a preselected value and adjusts it by means of the control elements (b-e) attached to the working pressurized Dewar vessel (a) or the

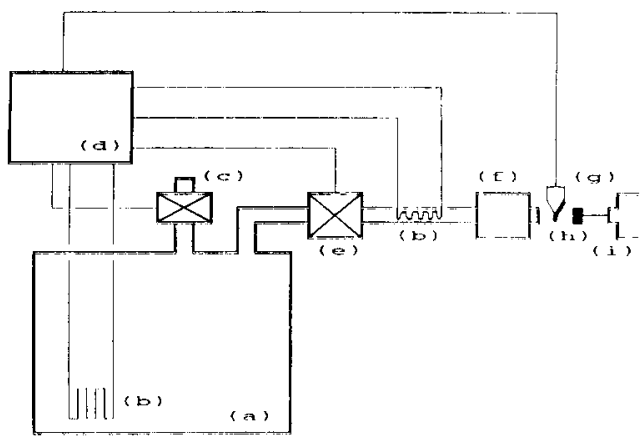

Figure 6. Automatic temperature control system with different control elements: (a) evaporation vessel; (b) electrical heater; (c) relief valve; (d) control unit; (e) electropneumatique control valve; (f) cooling nozzle; (g) thermocouple; (h) specimen; (i) goniometer head.

transfer line. Regulation of the heat input from the electric heater (b) can influence the gas flow rate as well as an electropneumatically operated cryogenic valve (e) or the outlet valve (c), working in the same way. Supplementary heating can be performed by a heating coil (b) inside the transfer line, ${ }^{27,62}$ or additionally mixing in a warm gas stream. ${ }^{22 b, 41,63}$ Depending on the requirements, only one or some of the described control elements are used, and even with manually controlled systems high temperature stability can be achieved. ${ }^{25}$

\section{Growth and Handling of Thermolabile Single Crystals}

\section{Crystal Growth in a Capillary}

This method was originally developed for substances that are liquids or gases at room temperature and in most cases performed directly on the X-ray instrument. The substance to be examined is sealed into a thinwalled glass capillary and frozen solid by the cold gas stream. A polycrystalline form is usually first obtained. For converting this into a single crystal, miniaturized versions of the well-known Bridgman, Stockenberger, or zone melting methods (for comparison of these methods see ref 16 and literature cited therein) are suitable. Application of these methods requires instrumentation for local heating or establishing a temperature gradient along the cooled capillary. Figure 7 shows the different experimental arrangements currently used.

Zone melting procedures are performed by moving a warm gas stream (e) from a fine nozzle (d) ${ }^{23 a, 25,64,65}$ or by driving an electrically heated filament (f) ${ }^{66-69}$ along the capillary filled with the polycrystalline material (b) and cooled by the cold gas stream (a). In another technique, ${ }^{70,71}$ heat radiation from a halogen lamp $(\mathrm{g})$ is focused by a parabolic mirror (h) onto the melting zone (c) of the capillary. The focus can be moved along the length of the capillary, while a simultaneous timedependent reduction of the lamp intensity and speed control of the movement may be chosen as parameters for the experiment. Programmed crystal growth by microprocessor-controlled equipment on a four-circle diffractometer has been carried out. ${ }^{71}$

Simon et al. established thermal gradients by applying a heated screen (i), which shielded parts of the capillary from the cold gas stream. ${ }^{72}$ This method was later modified for the four-circle diffractometer by introduction of a movable type screen connected to a 


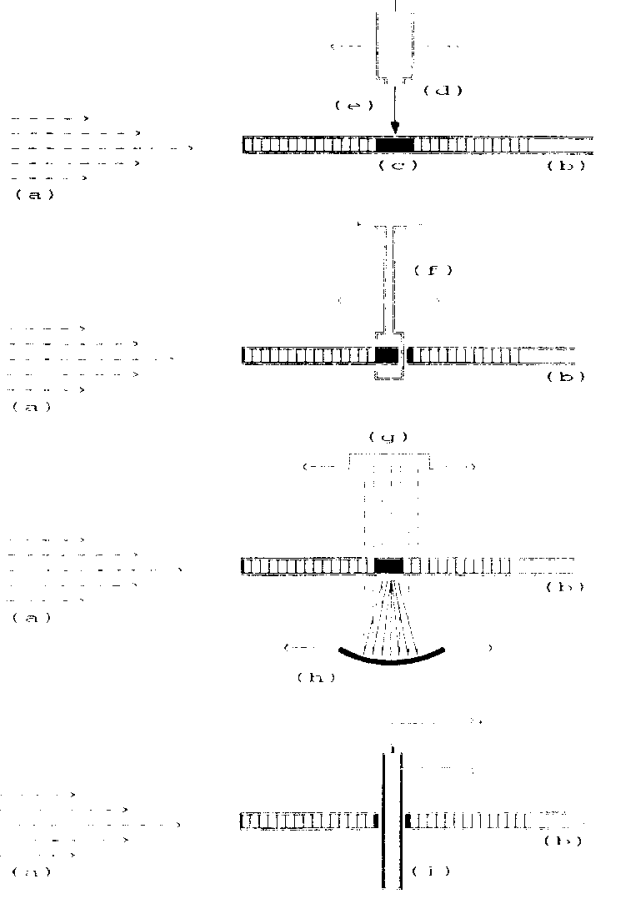

Figure 7. Methods for crystal growth in a capillary: (a) cold gas stream; (b) capillary with polycrystalline solid; (c) melting zone; (d) small nozzle; (e) warm gas stream; (f) electrically heated filament; (g) lamp; (h) focusing mirror; (i) electrically heated screen.

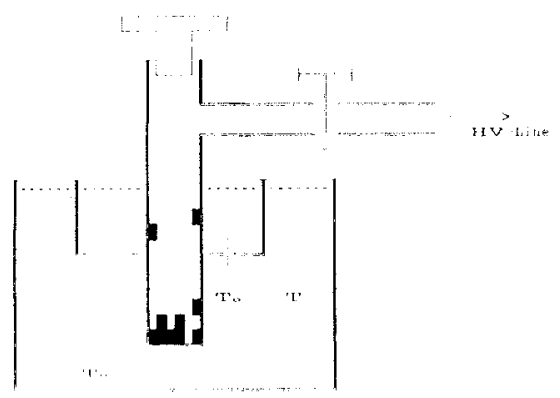

Figure 8. Crystal growth by low-temperature sublimation.

goniometer head. ${ }^{73}$ A similar technique had been employed early by Post et al., ${ }^{22 b}$ incorporating a small coil heater into the base of the specimen holder. Moving the capillary slowly in the cold gas stream ${ }^{74}$ and fine controlled changes of the gas stream temperature ${ }^{62}$ are further variations that have been applied to the single-crystal growth process.

In comparison to the growth from liquid or melt, single-crystal growth by vapor deposition in a capillary has not been used often, although Burbank ${ }^{39}$ stated some advantages of this method.

\section{Crystal Growth in One Place and Transfer to the Diffraction Device under Protective Conditions Elsewhere}

Special experimental requirements of the synthesis often make it impossible to grow single crystals of a thermolabile compound in a capillary directly at the place where the diffraction experiments are performed. In this case crystal growth may be performed by standard procedures, such as sublimation in vacuo or crystallization from solution after modification for the use at low temperature and under protective conditions.

Figure 8 shows an arrangement for low-temperature sublimation. A temperature gradient is established by
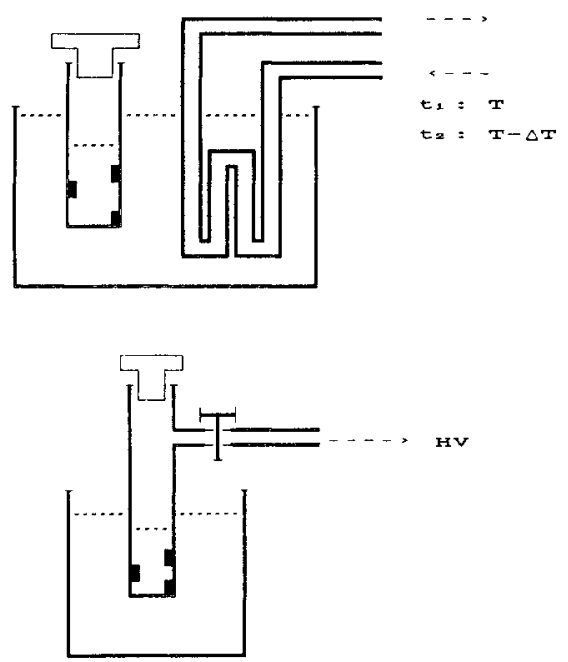

Figure 9. Crystal growth from solution.

means of two cooling baths maintained at different temperatures below the decomposition point of the sample. ${ }^{75}$

Crystallization from solution may be simply achieved by slowly cooling or by concentrating a solution in vacuo (see Figure 9).

A more complicated device involving a concentration gradient between two reservoirs held at different temperatures has been published ${ }^{76}$ but seems susceptible to difficulties in use with air-sensitive materials.

Single-crystal growth of thermolabile compounds in the described manner is not much more difficult to achieve than that of "normal" substances. Further handling of these crystals, such as collection, selection, sealing into capillaries, and transfer to and mounting at the diffraction device, requires extreme care and experimental skill, as the material has to be maintained continuously below its point of decomposition. Additional complications arise if the sample is sensitive to air and moisture. These must be the reasons why few examples of crystal growth at one place and transfer to another place have come to our knowledge. In addition to examples referring to this technique mentioned in chapter III, some work showing different approaches to master the problems stated above should be noted.

If the decomposition point of the material is not far below ambient temperature, growth, selection, sealing, and mounting of the crystals may be done in a refrigerated area..$^{7,78}$

Another method of approach was reported by Luzzati. $^{79} \mathrm{He}$ grew crystals of nitric acid trihydrate in a beaker suspended in an unsilvered Dewar by blowing cold gas between the walls of the beaker and the Dewar. The rate of crystallization was controlled by the cold gas flow rate. Excess liquid was removed with a pipet, and crystals were maintained by filling the Dewar with dry ice. A specimen was transferred to a cold metal plate with refrigerated tweezers, examined, connected to an aluminum wire filament, and mounted on the $\mathrm{X}$-ray device in a cold gas stream.

Crystals of valeric acid were grown at dry ice temperature, examined, and sealed on a metal plate cooled by a block of dry ice; a piece of dry ice was used also for the transfer to the cold gas stream of the X-ray device. ${ }^{80}$

Selection and sealing of cyclopentadiene crystals were carried out under liquid nitrogen. ${ }^{81}$ 

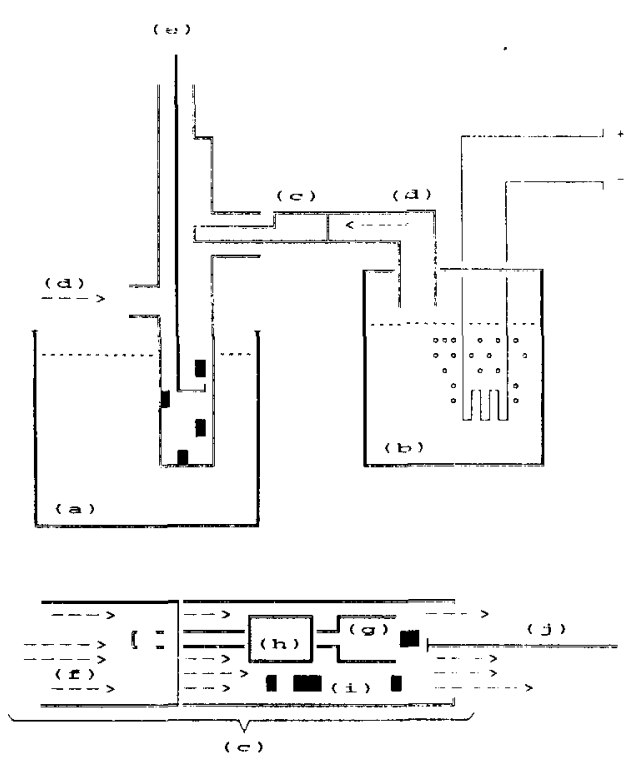

Figure 10. Transfer of thermolabile specimen to capillaries: (a) cooling bath; (b) crystal selection and capillary filling apparatus; (c) selection and capillary filling tube; (d) cold gas streams; (e) "metal transfer spoon"; (f) cold gas stream; (g) capillary; (h) connection element to goniometer head; (i) specimens for choice; (j) glass filament.

Crystals of the low-temperature form of hydronium perchlorate were grown from a water-anhydrous perchloric acid mixture at dry ice temperature and were selected on a microscope cold stage, cooled from below and blanketed with dry nitrogen gas. During the insertion of a crystal, a glass capillary was held in a hole of a block of dry ice. After sealing, the capillary was transferred from the dry ice directly to the cold gas stream of the X-ray device. ${ }^{82}$ Formerly the same author prepared crystals of the low-temperature form of ammonia-triborane by evaporation of a diethyl ether solution of the compound while maintaining under a slow stream of dry nitrogen in a vial immersed in a chlorobenzene slush bath at $-45^{\circ} \mathrm{C}$. The crystals were selected and mounted in a similar way to that mentioned above. ${ }^{83}$

All these early methods were adjusted to the special requirements of the related problems but no generally applicable procedure has been given. The method used in 1974 by Veith and Bärnighausen in the study of the structure of bis(trimethylsilyl)diimine ${ }^{84}$ has been developed to a standard procedure today for the handling of thermolabile, air- and moisture-sensitive single crystals. It has proved successful in many investigations, some of which are discussed in chapter III from a chemical viewpoint. A variant is described below that was used also recently during the structural investigation of bis(ethene)(toluene)iron. ${ }^{85}$ The principles are illustrated in Figure 10. The central element of the arrangement is the crystal selection and capillary filling apparatus (b), consisting of a small electrical evaporation cold gas supply unit equipped with the crystal selection and capillary filling tube (c). This is simply the half-section of a thin-walled aluminum tube. ${ }^{84} \mathrm{~A}$ glass capillary $(\mathrm{g})$, cemented to a small metal cylinder (h) serving as a connection element to a goniometer head, is dried in a vacuum line and transferred into the cold gas stream flowing along (c). Then (c) is inserted into the crystal growth container as shown in Figure 10. A second cold gas stream protects the crystalline ma- terial while being transferred to (c) with a cold metal spoon (e). The cold stream of dry gas in (e) protects the dried capillary and the crystals from air and moisture when (b) is removed from the container. Suitable single crystals are selected with the aid of a microscope, and a glass filament (j) may be used to insert one of them into the capillary. In most cases after some attempts a crystal of appropriate size can be deposited in the capillary behind the goniometer head connection element $(h)$. The open end of the capillary is then removed from the cold gas stream and sealed by melting it with the flame of a very small torch.

When the selection and sealing process has been performed, connection of the electrical heater to a battery changes the crystal selection and capillary filling apparatus (b) to a portable transport and mounting support apparatus. This enables the sealed capillary to be transferred to the X-ray equipment, where it can be moved from the protective cooling gas stream directly into the cooling gas stream of the X-ray device. In the course of a structural investigation some crystals often have to be examined. It may thus be convenient to seal a number of crystals and deposit them for some time onto dry ice or another suitable cooling agent. ${ }^{52}$

Extremely air- and moisture-sensitive compounds with decomposition points as low as $-80^{\circ} \mathrm{C}$ have been successfully examined in the way described (see chapter III for examples), and we consider that the method would also work down to -120 or $-130^{\circ} \mathrm{C}$, as it is possible to maintain the samples all the time below this temperature.

A selection and capillary filling technique similar to the one described by Veith and Bärnighausen ${ }^{84}$ has been used more recently in the structural investigation of squalene. ${ }^{76}$

\section{Use of Three-Dimenslonal Structures of Unstable Inorganic Molecules and Solids in the Evaluation of Their Reactivity}

\section{A. Correlation of Instability and Molecular Structure}

Bis(trimethylsilyl)diimine, ${ }^{86}$ a derivative of diazene (diimine), readily decomposes at -20 to $-35^{\circ} \mathrm{C}$ according to eq 3.

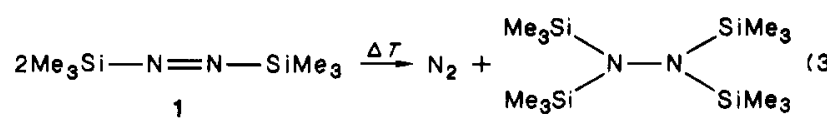

It is surprising that the silyl compound decomposes at about $80-100^{\circ} \mathrm{C}$ lower than the corresponding organic derivative bis(tert-butyl)diazene, although the $\mathrm{Si}-\mathrm{N}$ bond is usually believed to be much stronger than the $\mathrm{C}-\mathrm{N}$ single bond due to the multiple-bond character of $\mathrm{Si}-\mathrm{N}$ resulting from $\mathrm{p} \pi \rightarrow \mathrm{d} \pi$ interactions. ${ }^{87}$

Structure determination ${ }^{84}$ of 1 at $-130^{\circ} \mathrm{C}$ (the crystals were prepared following one of the routes described in chapter II.C.2) reveals a trans configuration of the azo group in the molecule and above all an extremely short N-N bond length (see Figure 11), which correlates well with the ease of nitrogen formation. It also exploits the understanding of the reactivity of the molecule. Migration of the trimethylsilyl group from one nitrogen atom to the other within 1 should be very plausible considering the geometry of the molecule and the long 


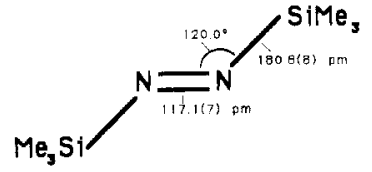

Figure 11. Molecular dimensions in $\mathrm{Me}_{3} \mathrm{Si}-\mathrm{N}=\mathrm{N}-\mathrm{SiMe}_{3} .{ }^{84}$
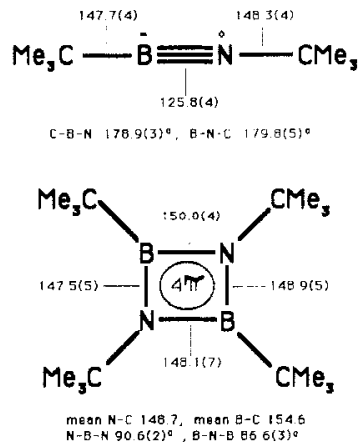

Figure 12. Intramolecular distances (pm) in tert-butyl(tertbutylimino) borane (4) and its cyclic dimer (5). ${ }^{90}$

bond distance between $\mathrm{Si}$ and $\mathrm{N}$. The dimerization of 1 to the (trimethylsilyl)tetrazene 2 (which occurs under reaction conditions different from those in (j)) or the complex formation of 1 with dicyclopentadienylvanadium, yielding a stabilized isodiazene 3 in this context, is therefore not surprising (eq 4).

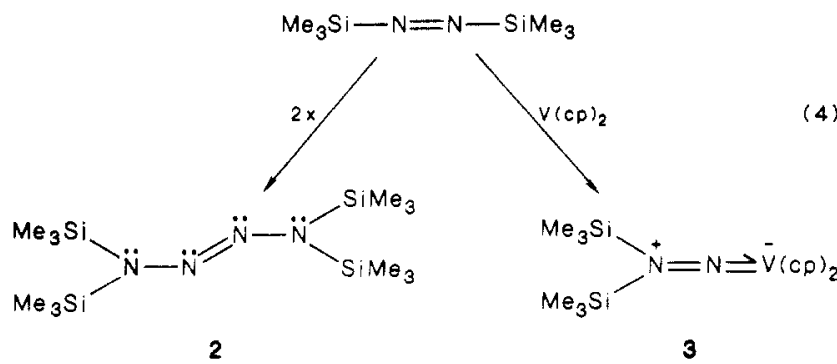

The structure of $2^{88}$ and $3^{89}$ also have been confirmed by X-ray structure analysis. It should be noted further that the low temperature, necessary for a diffraction experiment on 1 or other compounds, reduces the molecular motion of the atoms within the crystal. ${ }^{1}$ Hence the data are less affected by dynamics and the structure is substantiated with great accuracy. In the case of the $\mathrm{X}$-ray structure determination of 1 , all hydrogen atoms have been unambiguously located within the crystal. The stereochemical activities of the lone pairs of the nitrogen atoms in 1 can be shown ${ }^{84}$ by simple analysis of interatomic nonbonding distances. Their location can be compared with results from theoretical calculations. ${ }^{84}$

In Figure 12 the intramolecular distances of tert-butyl(tert-butylimino)borane (4) are shown together with those of its cyclic dimer (5) ${ }^{90}$ With respect to the isoelectronic acetylene derivative, the rather long $\mathrm{B}-\mathrm{N}$ triple bond within $4(\Delta=8 \mathrm{pm})$ and its obvious polarity (dipole moment of $4=0.020 \pm 0.003 \mathrm{D}$ ) induce a greater reactivity. 4 is metastable $\left(t_{1 / 2}\left(50^{\circ} \mathrm{C}\right)=3\right.$ days $\left.^{90}\right)$ and cyclizes slowly to its dimer, the 1,3,2,4-diazadiboretidine 5. Crystals of 4 were obtained by zone melting and recrystallization, whereby IR radiation was used for heating. 4 originates by thermolysis of 6 as educt at 530 ${ }^{\circ} \mathrm{C}$ and is quenched at $-196{ }^{\circ} \mathrm{C}$ (eq 5).

In comparison to tetra-tert-butylcyclobutadiene, ${ }^{91}$ the $\mathrm{B}_{2} \mathrm{~N}_{2}$ cycle in 5 is, remarkably, more folded and thus

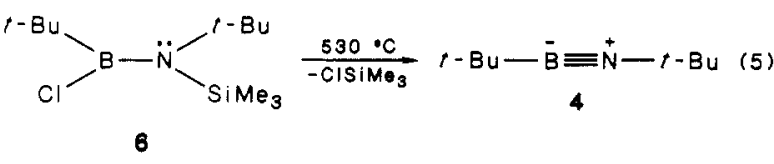

deviates significantly from planarity. Also, the four $\mathrm{B}-\mathrm{N}$ bond lengths in 5 are equal within the limits of standard error, whereas in the cyclobutadiene they differ more (146.4 (2) vs 148.2 (2) pm). The mean B-N bond distance in the $\mathrm{B}_{2} \mathrm{~N}_{2}$ cycle is $18.14 \%$ larger than the $\mathrm{B}-\mathrm{N}$ bond length in the monomeric iminoborane. If the corresponding $\mathrm{C}-\mathrm{C}$ distances in the tert-butylsubstituted cyclobutadiene and the acetylene are compared, the elongation amounts to $24.87 \% .{ }^{91}$ All these values can be interpreted in a greater reactivity of 4 compared to di-tert-butylacetylene.

Another example of a dimerization, where the structures of the reactant and the product have been established, is the trifluoroethylidynesulfur trifluoride, $\mathrm{F}_{3} \mathrm{C}-\mathrm{C} \equiv \mathrm{SF}_{3}(7)$, and its transformation to the dimer 8. ${ }^{92}$

At low temperatures $\left(-100\right.$ to $\left.-150^{\circ} \mathrm{C}\right)$, crystal growth of the monomer can be achieved in a capillary from the melt. In the same capillary, dimerization takes place at elevated temperatures, but is terminated early enough to yield a concentrated solution of the dimer of $\mathrm{CF}_{3} \mathrm{C} \equiv \mathrm{SF}_{3}$. Crystals can then be grown from this solution. The fascinating aspect of this procedure is that chemical reactions are performed in a capillary and the products are probed by single-crystal techniques.

It can be shown by this experiment that the expected dimers 9,10 , and 11 are not formed; instead compound 8 with a central $\mathrm{C}-\mathrm{C}$ double bond and $\mathrm{SF}_{3}$ ligands is isolated.

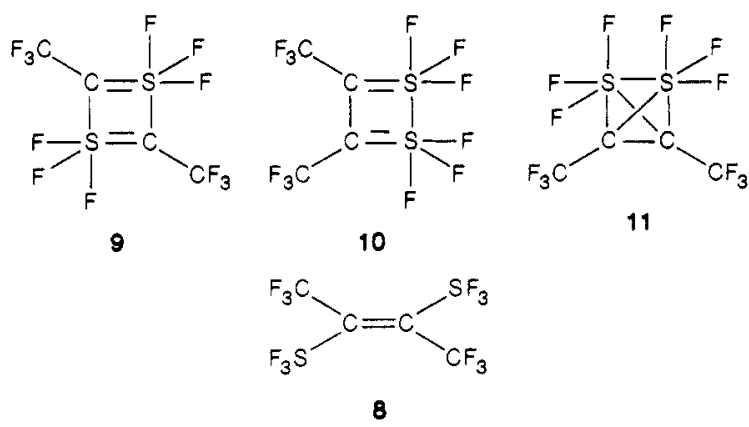

The reactivity of 7 can at least be partly attributed to its molecular structure. ${ }^{92}$ The molecule exhibits a very short $\mathrm{C} \equiv \mathrm{S}$ bond (139.4 pm), but is not perfectly linear regarding the $\mathrm{C}-\mathrm{C} \equiv \mathrm{S}$ arrangement. The angle at the central carbon atom of $171.5^{\circ}$ does not seem to be negligible in describing the bonding situation.

The following three mesomeric forms must be considered, of which the carbenoid ylidic description best reflects the reactivity.

$$
\mathrm{F}_{3} \mathrm{C}-\mathrm{C} \equiv \mathrm{SF}_{3} \longrightarrow \mathrm{F}_{3} \mathrm{C}-\ddot{\ddot{\mathrm{C}}}=\stackrel{+}{\mathrm{S}} \mathrm{F}_{3} \rightarrow \mathrm{F}^{-} \mathrm{F}_{2} \mathrm{C}=\mathrm{C}=\stackrel{+}{\mathrm{S}} \mathrm{F}_{3}
$$

The formula with a negative charge on the fluorine takes into consideration hyperconjugation in order to explain the rather short $\mathrm{C}-\mathrm{C}$ bond within 7 (131.9 (6) $\mathrm{pm}$ ).

A very instructive example for the use of the lowtemperature X-ray structure techniques is the cyclodimerization of 1,3-di-tert-butyl-2,2-dimethyl$1,3,2,4 \lambda^{2}$-diazasilastannetidine (12). ${ }^{93}$ This amino compound of divalent tin may crystallize in one of two 

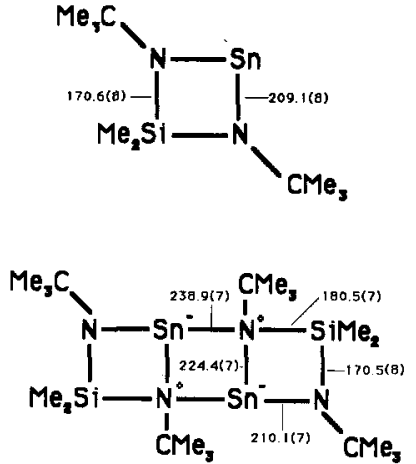

Figure 13. Comparison of the molecular dimensions (pm) in $\mathrm{Me}_{2} \mathrm{Si}(\mathrm{N}-t-\mathrm{Bu})_{2} \mathrm{Sn}$ and $\left[\mathrm{Me}{ }_{2} \mathrm{Si}(\mathrm{N}-t-\mathrm{Bu})_{2} \mathrm{Sn}\right]_{2}{ }^{94}$

different solid modifications. A pale yellow, triclinic phase is obtained when pure (at ordinary temperature) red liquid 12 is allowed to cool below $0{ }^{\circ} \mathrm{C}$. Whereas the liquid almost exclusively contains monomeric molecules, the triclinic solid consists of dimers. ${ }^{93}$ This phenomenon can be explained by an intramolecular reaction as formulated in eq 6 .

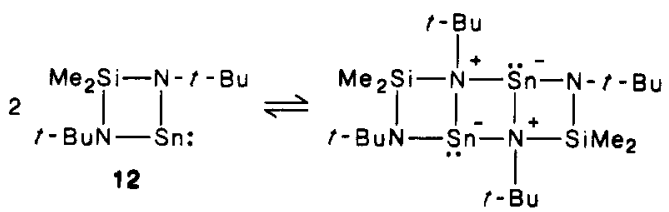

On the other hand, an orange monoclinic phase forms when 12 is first dissolved in hexane and crystallization is induced at $-70^{\circ} \mathrm{C}$. The two solid phases of 12 cannot be mutually converted into one another: on heating, the orange monoclinic form melts and recooling yields the triclinic one. In contrast to the triclinic phase, the monoclinic phase contains monomeric and dimeric molecules in a 1:1 ratio, as has been established by a low-temperature X-ray structure determination. ${ }^{94}$ The intermolecular reciprocal actions of the molecules, which are more frequent in a melt than in a solution, apparently seem to influence the balance of the equilibrium (6). As a matter of fact, the structure determination of the monomer 12 has been possible only by the techniques described in chapter II.C.

In Figure 13 the most important structural dimensions of the monomer and the dimer are depicted. As can be seen from this comparison the dimerization of 12 occurs at the expense of the $\mathrm{Sn}-\mathrm{N}$ and $\mathrm{Si}-\mathrm{N}$ bond lengths of the monomer. This fact may be compared with the oligomerization of molecules with $\sigma, \pi$ double bonds (see above; for further discussion of this general aspect, see ref 95 ).

Finally, we have recently found a case in which even intramolecular contacts must be considered to explain the instability of the molecule. 2-Tetrazene, which has been synthesized by Wiberg and co-workers, ${ }^{96}$ is not stable above $-30^{\circ} \mathrm{C}$. Solid 2-tetrazene decomposes to, among other products, the isomeric compound $\mathrm{NH}_{4} \mathrm{~N}_{3}$. This transformation was not fully understood. ${ }^{96}$ The $\mathrm{NH}_{4} \mathrm{~N}_{3}$ could have been formed by an intramolecular or an intermolecular ${ }^{86,96}$ hydrogen migration. The crystal structure determination of $\mathrm{H}_{2} \mathrm{~N}-\mathrm{N}=\mathrm{N}-\mathrm{NH}_{2}$ at low temperature ${ }^{75}$ also gave some insight into this problem. In addition to the interesting molecular features it was found that the molecules in the lattice interact via extraordinarily strong $\mathrm{N}-\mathrm{H}$... $\mathrm{N}$ hydro- gen-bridged bonds. These findings may be correlated with an intermolecular hydrogen transfer yielding in this way $\mathrm{NH}_{3}$ and $\mathrm{HN}_{3}$, which then combine in a separate step to give $\mathrm{NH}_{4} \mathrm{~N}_{3}$.

\section{B. Reaction Intermedlates}

The molecules, which have been discussed in the previous chapter, may all be considered as intermediates in a sequence of reactions. In this context the structure determination of the unstable molecule serves as confirmation of the existence of the compound. This may be illustrated by another, organometallic example. ${ }^{85}$ Following eq 7, cocondensation of $\mathrm{Fe}$ and toluene
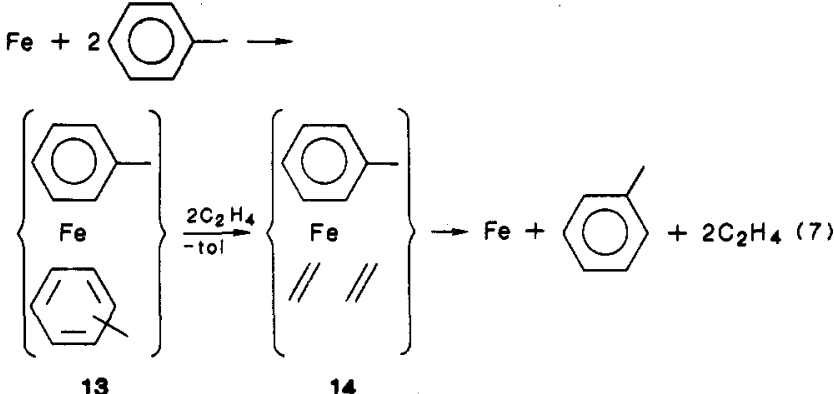

yields the bis(toluene)iron complex 13 , from which one toluene can be replaced by two ethene molecules. Compound 14 has been isolated at $-78^{\circ} \mathrm{C}$ as orange crystals, which decompose above $-50^{\circ} \mathrm{C}$ to iron, ethene, and toluene.

It is comparatively easy to find out by spectroscopic methods that 13 is a $\left(\eta^{6}\right.$-arene $)\left(\eta^{4}\right.$-arene)iron $(0)$ type complex, ${ }^{97,98}$ but the ${ }^{1} \mathrm{H}$ NMR of 14 gives broad resonances (effected by partial decomposition) that cannot be interpreted with certainty in terms of a molecular structure. By low-temperature X-ray diffraction compound 14 is unambiguously characterized as bis $\left(\eta^{2}-\right.$ ethene)( $\eta^{6}$-toluene)iron. The structure determination confirms that 14 is a molecular intermediate with a definite composition and also establishes the type of bonding of the ligands on the iron atom.

An even more complicated situation in the characterization of a transient intermediate occurs in the reaction of 1,3-di-tert-butyl-2,2-dimethyl-1,3,2,4 $\lambda^{2}$-diazasilastannetidine with tert-butylamine. However, this also has been solved by using the techniques described in this review. ${ }^{99}$ If equimolar amounts of 12 and the amine are allowed to react, three different compounds $(15,16$, and 17) are formed (eq 8).

$$
\begin{aligned}
5 \mathrm{Me}_{2} \mathrm{Si}(\mathrm{N}-t-\mathrm{Bu})_{2} \mathrm{Sn} & +5-t-\mathrm{BuNH}_{2} \rightarrow \\
4 \mathrm{Me}_{2} \mathrm{Si}(\mathrm{N}-t-\mathrm{BuH})_{2} & +\mathrm{Me}_{2} \mathrm{Si}(\mathrm{N}-t-\mathrm{Bu})_{2} \mathrm{Sn} \cdot \mathrm{SnN}-t-\mathrm{Bu} \\
\mathbf{1 5}+(\mathrm{SnN}-t-\mathrm{Bu})_{2} \cdot\left(\mathrm{Sn}(\mathrm{N}-t-\mathrm{BuH})_{2}\right) &
\end{aligned}
$$

17

By variation of the molar ratio of 12 and tert-butylamine, either 16 or 17 can be obtained, together with 15. ${ }^{100}$ The formation of $\mathbf{1 6}$ and $\mathbf{1 7}$ seems to be explicable by assuming a transient iminostannylene $\{t$ BuNSn:\}, ${ }^{101}$ a heavy congener of tert-butyl isocyanide (see also ref 102). In order to gain insight into the reaction mechanism, we steadily lowered the temperature of the hexane solution containing the reactants 12 and tert-butylamine in equimolar amount. At $-80^{\circ} \mathrm{C}$ single crystals of the 1:1 complex of 12 and tert-bu- 


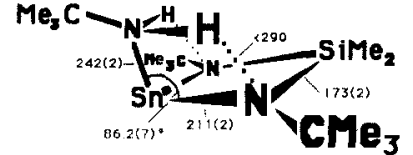

Figure 14. Molecular structure of $\mathrm{Me}_{2} \mathrm{Si}(\mathrm{N}-t-\mathrm{Bu})_{2} \mathrm{Sn} \cdot \mathrm{H}_{2} \mathrm{~N}-t-\mathrm{Bu} .^{99}$ Distances in picometers; angles in degrees.

tylamine (18) were obtained.99 They were used for an X-ray structure determination revealing the unstable 18 to be a Lewis acid-base adduct, in which the nitrogen atom of the amine coordinates to the nucleophilic tin atom (Figure 14). Moreover, we found that the hydrogen atoms of the amine are in the near vicinity of the nitrogen atoms in the $\mathrm{SiN}_{2} \mathrm{Sn}$ ring, the latter even protruding by $22 \mathrm{pm}$ from the $\mathrm{SiN}_{2} \mathrm{Sn}$ plane. In order to explain the formation of $\mathbf{1 5}$ and of the transient iminostannylene, the hydrogen atoms only need to migrate along the $\mathrm{N} \cdots \mathrm{H}$ interactions by about $150 \mathrm{pm}$ (eq 9 ).
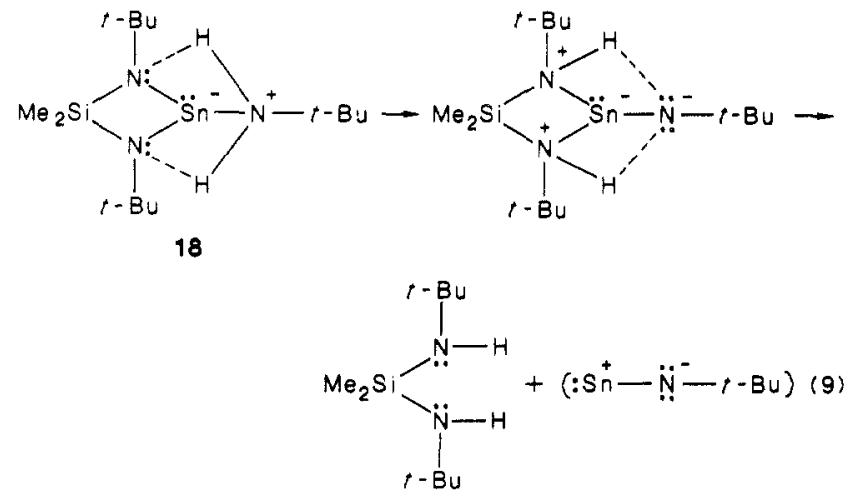

15

The N...H bonds within 18 thus can be considered as reaction coordinates. The resulting iminostannylene, which may exist free or coordinated, is subsequently trapped by 12 to form 16 or by tert-butylamine to form 17 (for more details, see ref 101 ).

\section{Unstable Phases in Solld-State Chemistry}

As pointed out in the introduction, low-temperature $\mathrm{X}$-ray diffraction techniques have been used in solidstate chemistry for a considerable time. Metastable phases have been characterized, temperature-dependent disorder-order transitions in plastic or liquid crystalline phases have been followed, structure-dependent changes in physical properties with decreasing temperature have been investigated, etc. References to these and other subjects may be found in the monograph of Rudman. ${ }^{1}$. Difficulties that are frequently encountered are unfavorable phase diagrams for growing crystals, twinning, and the occurrence of antiphase boundaries.

Although it is not the subject of this review to focus on this special topic, it should, nevertheless, be pointed out that entire fields of inorganic solid-state chemistry are dependent on low-temperature X-ray techniques. We wish to demonstrate this in three examples. The alkali metal suboxides, which were claimed to exist at the beginning of this century, ${ }^{103}$ have only recently been chemically and structurally characterized. ${ }^{104,105}$ To set up phase diagrams for crystal growth, Simon had to develop a new X-ray camera for polycrystalline powders at low temperatures, ${ }^{106}$ which is now commercially available. ${ }^{107}$ The structures of water-rich mineral acids also can be determined only at low temperatures because of their low melting points. In a recent publication, Mootz et al. showed that even the metastable $\mathrm{H}_{2} \mathrm{SO}_{4} \cdot 8 \mathrm{H}_{2} \mathrm{O}\left(\left(\mathrm{H}_{5} \mathrm{O}_{2}\right)_{2} \mathrm{SO}_{4} \cdot 4 \mathrm{H}_{2} \mathrm{O}\right)$ can be characterized. ${ }^{108}$ Finally, Simon et al. succeeded not long ago in crystallizing the $\beta$-form of white phosphorus and were able to obtain the three-dimensional structure. ${ }^{109}$ Whereas the $\beta$-form is ordered, with six tetrahedral $\mathrm{P}_{4}$ molecules within the centrosymmetric triclinic lattice, the $\alpha$-form is cubic and disordered (plastic crystalline phase). ${ }^{110}$ Since single crystals of $\beta$-P cannot be obtained by cooling $\alpha$-P crystals below the transition temperature of $-76.4^{\circ} \mathrm{C}$ (see references in ref 109), they grew $\beta$-P crystals directly from a $\mathrm{CS}_{2}$ solution between -80 and $-110^{\circ} \mathrm{C}$, thus avoiding the formation of $\alpha-\mathrm{P}$. This experiment demonstrates that the techniques described in chapter II.C for unstable molecular compounds may be relevant even in solid-state chemistry.

\section{Conclusion and Outlook}

Low-temperature techniques in combination with $\mathrm{X}$-ray diffraction may serve as tools for the structural characterization of unstable molecules. Crystal growth and transfer of the metastable crystalline solids have been described. As these techniques are not restricted to a capillary, they should be of general application to any chemical problem concerned with an unstable or transient molecular compound. The impact on the detection of reaction mechanisms is obvious.

\section{Acknowledgments}

We are grateful for financial support from the Fonds der Chemischen Industrie and the Deutsche Forschungsgemeinschaft. We thank Prof. M. Ashworth for reading the manuscript and for the English corrections.

\section{References}

(1) Rudman, R. Low Temperature X-Ray Diffraction: Apparatus and Techniques; Plenum: New York, 1976.

(2) (a) Rev. Chem. Intermed. (b) React. Intermed. (Plenum).

(3) (a) Rossiter, B. W., Ed. In Chemical Experimentation under Extreme Conditions; Wiley: New York, 1980. (b) Klabunde, K. J. In Chemistry of Free Atoms and Particles; Academic: New York, 1980. (c) Gaspar, P. P. React. Intermed. (Plenum) $1985,3,333$

(4) (a) Davis, M. Electron Diffraction in Gases; Dekker: New York, 1971. (b) Seip. H. M. In Molecular Structure by Diffraction Methods; Sim, G. A., Sutton, L. E., Eds.; The Chemical Society: London, 1973; Vol. 1, p 7. (c) Robiette, G. A. In Molecular Structure by Diffraction Methods; Sim, G. A., Sutton, L. E., Eds.; The Chemical Society: London, 1973; Vol. 1, p 160. (d) Haaland, A.; Vilkov, L.; Kharkin, L. S.; Yokozeki, A.; Bauer, S. H. Top. Curr. Chem. 1975, 53, 1 , 25,71 .

(5) (a) Turner, D. W.; Baker, A. D.; Baker, C.; Blundle, C. R. Molecular Photoelectron Spectroscopy; Wiley-Interscience: London, 1970. (b) Carlson, T. A. Photoelectron and Auger Spectroscopy; Plenum: New York, 1975.

(6) (a) Jaffe, H. H.; Orchin, M. Theory and Applications of Ultraviolet Spectroscopy; Wiley: New York, 1962. (b) Herzberg, G. Electronic Spectra of Polyatomic Molecules Van Nostrand: London, 1966. (c) Brundle, C. R.; Baker, A. D., Eds. Electron Spectroscopy: Theory, Techniques and Applications; Academic: London, 1977-1981; Vol. I-IV.

(7) Kroto, H. W. Molecular Rotation Spectra; Wiley: London, 1975.

(8) (a) Meyer, B. Low Temperature Spectroscopy; American Elsevier: New York, 1971. (b) Barnes, A. J.; Orville-Thomas, W. J.; Muller, A.; Gaufrês, R., Eds. Matrix Isolation Spectroscopy; Reidel: London, 1980. (c) Downs, A. J.; Hawkins, M. Adv. IR Raman Spectrosc. 1983, 10, 1. (d) Breeze, P. A. New Scientist 1983, 106, 146.

(9) (a) Herzberg, G. Infrared and Raman Spectra of Polyatomic Molecules; Van Nostrand: New York, 1966. (b) Weidlein, J; 
Müller, U.; Dehnicke, K. Schwingungsspektroskopie-Eine Einführung; Thieme: Stuttgart, 1982, and literature cited therein. (c) Willner, H. Z. Anorg. Allg. Chem. 1981, 481, 117 . (d) Downs, A. J.; Peake, S. C. Molecular Spectroscopy; The Chemical Society: London, 1973; Vol. 1, p 523.

(10) (a) Mosteovits, M.; Ozin, G. A., Eds. Cryochemistry; Wiley: New York, 1976. (b) Perry, D. L.; Meier, P. F.; Hauge, R. H. Margrave, J. L. Inorg. Chem. 1978, 17, 1364. (c) Michl, J. Int. J. Mass. Spectrom. Ion Phys. 1983, 53, 255.

(11) (a) Pople, J. A.; Schneider, W. G.; Bernstein, H. J. HighResolution Nuclear Magnetic Resonance; McGraw-Hill: New York, 1959. (b) Kaplan, J. I.; Fraenkel, G. NMR of Chemically Exchanging Systems; Wiley-Interscience: New York, 1980.

(12) (a) Andrew, E. R. Prog. Nucl. Magn. Reson. Spectrosc. 1971 8, 1. (b) Mansfield, P. Prog. Nucl. Magn. Reson. Spectrosc. 1971, 8, 42. (c) Mehring, M. Principles of High Resolution NMR in Solids, 2nd ed.; Springer: Berlin, 1983.

(13) (a) Carlson, T. A. Photoelectron and Auger Spectroscopy Plenum: New York, 1975. (b) Fiermans, L.; Veunik, J.; Dekeyser, W., Eds. Electron and Ion Spectroscopy of Solids; Plenum: New York, 1978.

(14) (a) Greenwood, N. N.; Gibbs, T. C. Mössbauer Spectroscopy Chapman and Hall: London, 1971. (b) Gütlich, P.; Link, R.; Trautwein, A. Mössbauer Spectroscopy and Transition Metal Chemistry; Springer: Berlin, 1978, and literature cited therein.

(15) Weiss, A.; Witte, H. Kristallstruktur und Chemische Bindung; Verlag Chemie: Weinheim, 1983, and literature cited therein.

(16) West, A. R. Solid State Chemistry and Its Applications; Wiley: Chichester, 1984, and literature cited therein.

(17) Peiser, H. S.; Rooksby, H. P.; Wilson, A. S. C., Eds. X-ray Diffraction by Polycrystalline Materials; Chapman and Hall: London, 1955; Chapter 10.

(18) Rudman, R. Am. Lab. (Fairfield, Conn.) 1977, 9, 31.

(19) Robertson, J. M. J. Sci. Instrum. 1960, 37, 41.

(20) Cioffi, P. P.; Taylor, L. S. J. Opt. Soc. Am. 1922, 6, 906

(21) Eastman, E. D. J. Am. Chem. Soc. 1924, 46, 917.

(22) (a) Kaufman, M. S.; Fankuchen, I. Rev. Sci. Instrum. 1949 20,733. (b) Post, B.; Schwartz, R. S.; Fankuchen, I. Rev. Sci. Instrum. 1951, 22, 218. (c) Steinfink, H.; Ladell, J.; Post, B.; Fankuchen, I. Rev. Sci. Instrum. 1953, 24, 882

(23) (a) Abrahams, S. C.; Collins, R. L.; Lipscomb, W. N.; Reed, T. B. Rev. Sci. Instrum. 1950, 21, 396. (b) Reed, T. B.; Lipscomb, W. N. Acta Crystallogr. 1953, 6, 45 .

(24) Post, B. Low-Temperature X-ray Diffraction; International Union of Crystallography, Commission on Crystallographic Apparatus, Bibliography 2.

(25) Kreuger, A. Acta Crystallogr. 1955, 8, 348.

(26) (a) Owen, E. A.; Williams, G. J. J. Sci. Instrum. 1954, 31, 49 (b) Bellard, S.; Sheldrick, G. M. Acta Crystallogr. Sect. B 1978, B34, 1043. (c) Coppens, P.; Ross, F. K.; Blessing, R. H.; Cooper, W. F.; Larsen, F. K.; Leipoldt, I. G.; Rees, B.; Leonard, R. J. Appl. Crystallogr. 1974, 7, 315. (d) Oxford Instrument Co., Oxford, U.K. (e) Coppens, P.; Godel, I.; Sabine, T. M. Rev. Sci. Instrum. 1967, 38, 1333. (f) Air Products and Chemicals, Inc., Allentown, PA.

(27) Young, R. A. J. Sci. Instrum. 1966, 43, 449

(28) Mehl, R. F.; Barrett, C. S. Trans. Metall. Soc. AIME 1930, 89,575 .

(29) Abowitz, G.; Ladell, J. J. Sci. Instrum. 1968, 1, 113.

(30) Burbank, R. D.; Bensey, F. N. Report No. K-841, Carbide and Carbon Chemicals Co., U-25 Plant, Oak Ridge, TN, 1951.

(31) Altona, C. Acta Crystallogr. 1964, 17, 1282

(32) Dickens, B. U.S. Naval Propellant Plant, Report NPP/RR $66-9,1966$

(33) Hospital, M. Thesis, University of Bordeaux, Bordeaux, 1968.

(34) Rudman, R.; Godel, J. B. J. Appl. Crystallogr. 1969, 2, 109

(35) Frenz, B. A.; Enemark, J. H.; Schroeder, L. W.; Hodgson, D. J.; Robinson, W. T.; Loyd, R. J.; Ibers, J. A. J. Appl. Crystallogr. 1969, 2,112.

(36) Thaxton, C. B.; Jacobson, R. A. J. Phys. E, Sci. Instrum. $1970,3,245$

(37) Silver, L.; Rudman, R. Rev. Sci. Instrum. 1971, 42, 671

(38) van Bolhuis, F. J. Appl. Crystallogr. 1971, 4, 263.

(39) Burbank, R. D. J. Appl. Crystallogr. 1973, 6, 437.

(40) Owen, E. A.; Williams, G. I. J. Sci. Instrum. 1954, 31, 49

(41) Harding, T. T. Can. J. Chem. 1956, 34, 371.

(42) Olovsson, I. Ark. Kemi 1960, 16, 437.

(43) Prakash, A. Indian J. Pure Appl. Phys. 1966, 4, 362.

(44) Gobrecht, M.; Grawlik, D.; Grosse, R. J. Phys. E, Sci. Instrum. 1971, 4, 913

(45) Rudman, R. J. Appl. Crystallogr. 1972, 5, 143.

(46) Marsh, D. J.; Petsko, G. A. J. Appl. Crystallogr. 1973, 6, 76.

(47) Lippman, R.; Rudman, R. J. Appl. Crystallogr. 1976, 9, 220

(48) Universal Low Temperature Device for X-ray Diffraction Cameras and Diffratometers; Enraf-Nonius: Delft, Holland.

(49) The Rigaku Journal 1985, 2 (2), 18.

(50) Renaud, M.; Fourme, R. Acta Crystallogr. 1967, 22, 695.
(51) (a) Hope, M.; Furuseth, S.; Selte, K.; Kjekshus, A. ACA Winter Meeting Abstracts, B6, 1973. (b) P3/R3 Systems for $X$-ray Crystallography, Low Temperature Attachment; Nicolet XRD Corp.: Madison, WI.

(52) Schlemmer, G. Thesis, Universität Braunschweig, Braunschweig, FRG, 1982.

(53) Allen, W. W.; Jeffry, G. A.; McMullan, R. F. Rev. Sci. Instrum. 1963, 34, 300 .

(54) Cucka, P.; Singman, L.; Lovell, F. M.; Low, B. W. Acta Crystallogr., Sect. B 1970, B26, 1756

(55) Strouse, C. F. Rev. Sci. Instrum. 1976, 47, 871

(56) Abowitz, G.; Cath, P. G. J. Sci. Instrum. 1967, 44, 156.

(57) Drenth, W.; Wiebenga, E. H. Acta Crystallogr. 1955, 8, 755.

(58) Viswamitra, M. A. J. Sci. Instrum. 1962, 39, 381.

(59) Hori, T.; Matsuno, K. Acta Crystallogr., Sect. A 1972, A28, 247.

(60) Thewlis, J.; Davey, A. R. J. Sci. Instrum. 1955, 32, 79

(61) LaCour, T. Acta Crystallogr., Sect. B 1974, B30, 1642.

(62) Henshaw, D. E. J. Sci. Instrum. 1957, 34, 270.

(63) Huber, J. C. J. Phys. E, Sci. Instrum. 1969, 2, 294

(64) Rudman, R. Thesis, Polytechnic Institute of Brooklyn, Brooklyn, 1966.

(65) Rudman, R. J. Cryst. Growth 1970, 6, 163.

(66) Renaud, M.; Fourme, R. Bull. Soc. Fr. Mineral. Cristallogr. 1966, 89, 243 .

(67) Singh, A. K.; Ramaseshan, S. Proc. Indian Acad. Sci., Sect. A $1964,60,20$

(68) Huffman, J. C.; Streib, W. E.; Mueller, J. M. Proc. Am. Crystallogr. Assoc., Ser. 2 1973, 1, 156.

(69) Kravers, M. A.; Antipin, M. Y.; Kulishov, V. I.; Struchkov, Y. T. Sov. Phys.-Crystallogr. (Engl. Transl.) 1977, 22, 638

(70) von Dohlen, W. C.; Carpenter, G. B. Acta Crystallogr. 1955, 8,646 .

(71) Brodalla, D.; Mootz, D.; Boese, R.; Osswald, W. J. Appl. Crystallogr. 1985, 18, 316.

(72) Simon, A.; Brämer, W.; Hillenkötter, B.; Kuhlmann, H.-J. $Z$. Anorg. Allg. Chem. 1976, 419, 253.

(73) Simon, A.; Deiseroth, H.-J.; Westerbeck, E.; Hillenkötter, B. Z. Anorg. Allg. Chem. 1976, 423, 203.

(74) Parkes, A. S.; Hughes, R. E. Acta Crystallogr. 1963, 16, 734.

(75) Veith, M.; Schlemmer, G. Z. Anorg. Allg. Chem. 1982, 494, 7.

(76) Ernst, J.; Fuhrhop, J.-H. Liebigs Ann. Chem. 1979, 1635.

(77) Gopalakrishna, E. M.; Cartz, L. Acta Crystallogr., Sect. B $1972, B 28,2917$.

(78) Bertolucci, M. D.; Marsh, R. E. J. Appl. Crystallogr. 1974, 7,87 .

(79) Luzzati, V. Acta Crystallogr. 1953, 6, 152.

(80) Scheuerman, R. F.; Sass, R. L. Acta Crystallogr. 1962, 15, 1244 .

(81) Liebling, G.; Marsh, R. E. Acta Crystallogr. 1965, 19, 202.

(82) Nordman, C. E. Acta Crystallogr. 1962, 15, 18.

(83) Nordman, C. E.; Reiman, C. J. Am. Chem. Soc. 1959, 81, 3538.

(84) Veith, M.; Bärnighausen, H. Acta Crystallogr., Sect. B 1974, $B 30,1806$

(85) Zenneck, U.; Frank, W. Angew. Chem. 1986, 98, 806; Angew. Chem., Int. Ed. Engl. 1986, 25, 831.

(86) Wiberg, N. Angew. Chem. 1971, 83, 379; Angew. Chem., Int. Ed. Engl. 1971, 10, 374.

(87) (a) Bürger, H. Fortschr. Chem. Forsch. 1967, 9, 1. (b) Glidewell, C. Inorg. Chim. Acta Rev. 1973, 7, 69.

(88) Veith, M. Acta Crystallogr., Sect. B 1975, B31, 678.

(89) Veith, M. Angew. Chem. 1976, 88, 384; Angew. Chem., Int. Ed. Engl. 1976, 15, 387.

(90) Paetzold, P.; von Plotho, C.; Schmid, G.; Boese, R.; Schrader, B.; Bongeard, D.; Pfeiffer, U.; Gleiter, R.; Schäfer, W. Chem. Ber. 1984, 117, 1089.

(91) Irngartinger, M.; Riegler, N.; Malsch, K. D.; Schneider, K. A.; Maier, G. Angew. Chem. 1980, 92, 211.

(92) Pötter, B.; Seppelt, K.; Simon, A.; Peters, E.-M.; Hettich, B. J. Am. Chem. Soc. 1985, 107, 980

(93) Veith, M. Z. Naturforsch., B 1978, 33, 1

(94) Veith, M. Z. Naturforsch., $B$ 1978, 33, 7 .

(95) Veith, M. Angew. Chem. 1987, 99, 1; Angew. Chem., Int. Ed. Engl. 1987, 26, 1.

(96) Wiberg, N.; Bayer, H.; Bachhuber, H. Angew. Chem. 1975, 87, 222; Angew. Chem., Int. Ed. Engl. 1975, 14, 177.

(97) Parker, S. F.; Peden, C. H. F. J. Organomet. Chem. 1984, 272, 411.

(98) Morand, P. D.; Francis, C. G. Organometallics 1985, 4, 1653.

(99) Veith, M.; Schlemmer, G.; Sommer, M.-L. Z. Anorg. Allg. Chem. 1983, 497, 157

(100) Veith, M.; Sommer, M.-L.; Jäger, D. Chem. Ber. 1979, 112, 2581.

(101) Veith, M. Comments Inorg. Chem. 1985, 4, 4, 179.

(102) (a) Bock, H.; Dammel, R. Angew. Chem. 1985, 97, 128; Angew. Chem., Int. Ed. Engl. 1985, 24, 111. (b) Michl, J., et al., private communication. 
(103) Rengade, E. C. R. Seances Acad. Sci. 1909, 148, 1199.

(104) Simon, A. Crystal Structure and Chemical Bonding in Inorganic Chemistry; Rooymans, C. J. M., Rabenan, A., Eds.; North-Holland: Amsterdam, The Netherlands, 1975.

(105) Simon, A.; Deiseroth, H. J. Rev. Chim. Miner. 1976, 13, 98.

(106) Simon, A. J. Appl. Crystallogr. 1971, 4, 138.

(107) Enraf-Nonius, Delft, The Netherlands.
(108) Merschenz-Quack, A.; Mootz, D. Z. Kristallogr. 1986, 174, 143.

(109) Simon, A.; Borrmann, H.; Craubner, H. Proceedings of the 10th International Conference on Phosphorus Chemistry, Bonn, FRG, 1986.

(110) von Schnering, H. G. Angew. Chem. 1981, 93, 44; Angew. Chem., Int. Ed. Engl. 1981, 20, 33. 